\title{
A IMPORTÂNCIA DO PROJETO “CONSCIÊNCIA NEGRA” COMO INSTRUMENTO DE LUTA SOCIAL EM TAMANDARÉ - PERNAMBUCO
}

\author{
THE IMPORTANCE OF THE BLACK CONSCIOUSNESS PROJECT AS A SOCIAL FIGHTING \\ INSTRUMENT IN TAMANDARÉ - PERNAMBUCO
}

\author{
Maria do Carmo Ferrão SANTOS ${ }^{1}$ \\ Romero Silva de ALBUQUERQUE2
}

Artigo recebido em 26/04/2019 e aceito em 19/09/2019

\section{Palavras-chave:} Projeto Consciência Negra, preconceito racial, Tamandaré.

Keywords:

Project Black

Consciousness, racial prejudice, Tamandaré.

\section{R E S U M O}

A história da escravidão na capitania de Pernambuco iniciou no século XVI e está atrelada ao ciclo da cana-de-açúcar, onde escravos africanos serviam a seus senhores. Após a abolição da escravatura, em 1888, estima-se que algumas dezenas de ex-escravos optaram por residir em Tamandaré, uma região de praia que tinha como meio de sobrevivência apenas a pesca artesanal e a agricultura de subsistência. Como forma de contribuir com a alimentação dos moradores e familiares dos donos dos engenhos, escravos domésticos que desempenhavam funções de confiança com o seu dono, vinham pescar em Tamandaré. Com o passar do tempo houve uma evolução no setor turístico de Tamandaré, contribuindo com a migração de pessoas oriundas de várias localidades, trazendo consigo, ou não, a cultura da descriminação racial. Neste sentido, é que desde 2014, tem sido executado o Projeto Consciência Negra, com a finalidade de desconstruir o racismo. 0 objetivo deste trabalho é mostrar o Projeto Consciência Negra como instrumento de resistência e de luta, na tentativa de provocar empoderamento e sensibilização na sociedade de Tamandaré, assim como, conscientizar as pessoas negras sobre a importância do empoderamento e, mais do que aceitar é preciso despertar o sentimento de respeito não apenas nas pessoas negras, mas em toda a sociedade.

\begin{abstract}
A B S T RA C T
The history of slavery in the captaincy of Pernambuco began in the sixteenth century and is tied to the cycle of sugarcane, where African slaves served their masters. After the abolition of slavery in 1888 , it is estimated that a few dozen former slaves chose to reside in Tamandaré, a beach region that had as a means of survival only artisanal fishing and subsistence agriculture. As a way of contributing to the feeding of the villagers and relatives of the owners of the mills, domestic slaves who performed functions of trust with their owner, came to fish in Tamandaré. Over time, there has been an evolution in the tourist sector of Tamandaré, contributing to the migration of people from various locations, bringing with them or not the culture of racial discrimination. In this sense, it is that since 2014, the Black Consciousness Project has been executed, with the purpose of deconstructing racism. The objective of this work is to show the Black Consciousness Project as an instrument of resistance and struggle, in an attempt to provoke empowerment and sensitization in Tamandaré society, as well as to make black people aware of the importance of empowerment and, awaken the feeling of respect not only in black people, but in all of society.
\end{abstract}

\footnotetext{
${ }^{1}$ Bacharelado em Ciências Biológicas (UFRPE) e Licenciatura em Biologia (UFPE). Mestrado e Doutorado em Oceanografia Biológica (UFPE). Analista Ambiental do ICMBio/MMA. Professora. Pesquisadora de temas históricos sobre Tamandaré. Acadêmica efetiva e fundadora da Academia Tamandareense de Letras e Artes - ATLA. E-mail: mariacarmo.santos@icmbio.gov.br.

2 Licenciatura e Bacharelado em Educação Física (UNIVERSO-RECIFE). Pós-graduando em Educação Física Escolar (ESEF/UPE). Professor de Educação Física da rede Estadual de PE. Professor de capoeira. Representante do grupo Amigos do Frevo em Tamandaré. Participante do grupo de contação de história Samburá Encantado. Acadêmico efetivo e fundador da Academia Tamandareense de Letras e Artes - ATLA. E-mail: romero.capoeira@hotmail.com.
} 


\section{INTRODUÇÃO}

Quando os portugueses desembarcaram no Brasil imaginaram que teriam nos índios uma farta mão-de-obra, por serem grandes conhecedores deste território. Porém, eles não se submeteram ao trabalho forçado e intenso, principalmente nos engenhos de cana-de-açúcar, no entanto, devido à carência de pessoas para trabalhar nas atividades extrativas, os colonizadores decidiram escravizar os nativos. Por tudo isto, os povos indígenas passaram a considerar os brancos como inimigos, semelhantes às tribos rivais. Após os portugueses entenderem que os índios não correspondiam às expectativas, tornaram-se omissos ou incentivaram a sua exterminação.

Para explorar as riquezas naturais brasileiras, incentivar a colonização e a produção agrícola, além de obter incessantes lucros para enviar à Coroa portuguesa, os europeus optaram pelo sequestro do povo africano, que após a sua captura foram trazidos ao Brasil para viver como escravo. Os negros foram oriundos de diferentes regiões da África, portanto, tinham culturas e línguas diferentes. Nogueira (1998; p. 14) afirma que a distribuição era feita de forma que em um mesmo local não ficasse escravos da mesma região africana, para dificultar a comunicação entre eles, assim, com língua e cultura diferentes, inicialmente foi visível a aculturação.

Os africanos eram considerados pelos portugueses como pessoas sem raízes, assim, não foram inseridas na sociedade brasileira. Para Pinheiro (2017; p. 488) em sua resenha sobre Marcussi (2016), os negros nunca abandonaram a sua herança cultural africana, portanto, ao longo dos séculos desfizeram essa afirmativa de serem pessoas sem passado. Portanto, os fatos mostram que quanto maior a concentração de indivíduos com ascendência africana, mais africanizada era a comunidade em que viviam.

O senhor de escravos tinha um poder absoluto sobre a sua vida e morte, e neste sentido os castigos eram intensos. Com o passar do tempo, os escravos despertaram nos patrões o receio de que eles poderiam se rebelar e mata-los, juntamente com sua família e seus capatazes. Por outro lado, o branco era visto pelos negros como um inimigo em potencial, já que eram barbaramente castigados e mortos. Essas ameaças geraram um temor mútuo entre os dois grupos, e estes fatos deram origem ao sentimento de aversão, dominação e de exploração (NEABI, 2013; sp.). Embora de forma camuflada, o racismo ainda insiste em continuar, portanto, se perpetuando por gerações, já que infelizmente se entranhou nas mentes das pessoas que não se esforçam para aceitar as diferenças e conviver em harmonia com elas.

Apesar de a vergonhosa escravidão ter perdurado por séculos, o Brasil não se preparou para apoiar os afrodescendentes após o seu término, assim, não oficializou leis favoráveis para a inclusão social dos ex-escravos. Pelo contrário, logo após a abolição da escravidão, o país incentivou a migração de pessoas oriundas da Europa e Ásia, fato que diminuiu ainda mais a oportunidade dos 
afrodescendentes assumirem um espaço no mercado de trabalho e sua merecida valorização social e profissional. Assim sendo, continuaram a ser tratados com insignificância e se submeterem a progressivos preconceitos raciais.

Na região canavieira pernambucana, especialmente nas proximidades de Tamandaré, segundo relatos de antigos moradores, a abolição da escravatura, aparentemente só trouxe a liberdade jurídica, pois foi total a ausência de políticas públicas para integrar os ex-escravos na sociedade. Mesmo com a fundação de importantes usinas na zona rural (Central Barreiros, Cucaú e Santo André, respectivamente em 1890, 1895 e 1913), os negros continuaram inferiorizados, pois assumiam praticamente as mesmas funções na área de plantio dos engenhos e, pesados serviços braçais na indústria. Pelo exposto, eles sempre assumiram os postos mais baixos no litoral sul pernambucano, porém, o inverso acontecia com os europeus e seus familiares.

Tamandaré sempre teve vocação pesqueira, desde quando foi habitada pelos índios caetés, que eram exímios pescadores. Posteriormente, nas proximidades surgiram imensos engenhos de cana-deaçúcar, cujos proprietários consentiam que escravos e negros livres viessem pescar nos manguezais e no Atlântico, para abastecer a casa grande e os moradores. Neste universo escravista e intimamente relacionado com a pesca, os negros desempenharam um papel fundamental como primeiros ocupantes temporários desta praia. Com o passar do tempo, era comum a vinda de mestiços que passaram a morar em Tamandaré, em casas de taipas e cobertas com palhas de coqueiros. Porém, a subsistência dessas famílias dependia diretamente da pesca artesanal.

Foram crescentes as conexões estabelecidas entre Tamandaré e os afrodescendentes que se libertaram com a abolição da escravatura e aqui vieram residir, já que muitos senhores de engenhos da mata sul pernambucana não quiseram lhes pagar salários para continuarem trabalhando em suas propriedades. A vivência era harmoniosa entre os negros e mestiços, que originaram um pequeno povoado.

Com o passar do tempo foi crescendo a miscigenação populacional, principalmente a partir da década de 1950, quando Tamandaré começou a despertar interesse turístico, passando a ampliar a sua população e o comércio local. As famílias migraram de várias localidades, trazendo consigo a sua cultura e conceitos raciais. Neste entendimento das fronteiras étnicas houve um crescimento da sociedade branca economicamente dominante. 0 contingente populacional de negros não foi tornado invisível, mas aparentemente não conquistou espaço no mercado de trabalho em Tamandaré, principalmente nas vagas de apoio ao turismo de sol e mar, que atualmente representa uma importante fonte de emprego e renda.

0 preconceito racial, secularmente, tornou-se um problema estrutural da sociedade brasileira. Em Tamandaré, é relativamente harmonioso o compartilhamento dos espaços de trabalho e sociabilidade, onde a cada dia se busca respeito mútuo, como forma de luta. Neste sentido, como 
contribuição, é que desde 2014 tem sido executado o Projeto Consciência Negra, o qual está contribuindo de forma bastante positiva, na compreensão de igualdade entre as pessoas.

0 objetivo deste trabalho é mostrar a importância do Projeto Consciência Negra, como elemento de divulgação no sentido de provocar reflexão sobre o preconceito racial em Tamandaré, assim como, conscientizar as pessoas negras sobre a importância de assumirem e preservarem suas características naturais e culturais.

\section{METODOLOGIA}

As informações utilizadas para o desenvolvimento deste trabalho foram oriundas de pesquisas bibliográficas realizadas em periódicos, livros, sites especializados, teses e principalmente, bem como da vivência direta dos autores, entre 2014 - 2018, nas atividades preparatórias e dos dois momentos da culminância do Projeto Consciência Negra, ou seja, no dia 13 de maio (evento secundário) e 20 de novembro (evento principal). Somando-se a oito questionários semiestruturados que foram aplicados, visando melhor entender e divulgar o sentimento de algumas pessoas negras.

Os termos utilizados no presente trabalho foram: raças, racismos, descriminação e preconceito racial, empoderamento, consciência negra, Creche Padre Enzo e Tamandaré. As informações foram modeladas seguindo critério cronológico. Este parâmetro visa um melhor entendimento sobre a crescente participação da população de Tamandaré, favorável a este movimento sociocultural.

\section{HISTÓRICO DO MUNICÍPIO DE TAMANDARÉ}

Localizado no litoral sul de Pernambuco, o município ocupa uma área territorial de $214.307 \mathrm{~km}^{2}$, com cerca de 23.000 habitantes, destes, aproximadamente 70,0\% residem na cidade de Tamandaré (IBGE, 2018). No geral, as pessoas vivem da produção da pesca, da cana-de-açúcar, da agricultura familiar, do turismo e do comércio. Possui $16 \mathrm{~km}$ de orla, as matas atlântica, ciliar e de restinga, além de importantes manguezais. A palavra Tamandaré é de origem indígena, já que seus primeiros habitantes foram os índios caetés. Do vocábulo tupi, tamoindaré (tab-moi-inda-ré) significa o repovoador.

A primeira construção de Tamandaré foi uma trincheira de madeira e barro $\left(8^{\circ} 45^{\prime} 30^{\prime \prime} \mathrm{S}\right.$ e $35^{\circ} 05^{\prime} 55^{\prime \prime} \mathrm{W}$ ), no ano de 1645 , cujo local é considerado o marco zero, e tinha a função de proteger esta localidade durante a invasão holandesa (1630 a 1654), contou com a colaboração dos portugueses.

Tamandaré possui um farto patrimônio cultural, natural e histórico. Um fato interessante ocorreu em 13 de dezembro de 1859, quando esta localidade foi visitada por Dom Pedro II, estando a esquadra que o transportava sob o comando do vice-almirante Joaquim Marques Lisboa. Na ocasião este militar pediu permissão ao Imperador para levar os restos mortais do seu irmão, o major do 
exército Manuel Marques Lisboa, morto e sepultado no Forte de Tamandaré quando participou da Confederação do Equador, em 1824. Já no Rio de Janeiro, no dia 14 de março de 1860, Dom Pedro II concedeu a Joaquim Marques Lisboa o título de Barão (posteriormente, Visconde, Conde e Marquês) de Tamandaré, em homenagem ao povoado onde ficou guardado por mais de três décadas, os restos mortais do irmão do vice-almirante. Em 1867, quando Joaquim Marques Lisboa foi promovido a Almirante da Marinha de Guerra, o seu nome de nobreza já estava tão vinculado à sua pessoa, que o adotou também neste mais alto cargo militar, portanto, passou a ser chamado de Almirante Tamandaré. Este fato mostra que o Povoado de Tamandaré (atual município de Tamandaré), foi quem cedeu o seu nome ao Almirante Tamandaré.

Esta pequena Vila de Tamandaré, em 17 de maio de 1905, foi elevada à categoria de Distrito, pertencente ao município de Rio Formoso. Um primeiro impulso da sua ocupação ocorreu a partir da década de 1950, quando começou a prática do veraneio. Outro momento marcante do crescimento populacional foi entre as décadas de 1980 e 1990, com a implantação de vários loteamentos particulares, mas também populares apoiados por governos municipal e estadual. Tal fato proporcionou a vinda de centenas de famílias, além de estimular o crescimento do comércio local, especialmente o de apoio ao turismo.

Com toda essa evolução, em 1995, Tamandaré alcançou os pré-requisitos necessários para a sua emancipação. Esta foi conquistada por meio da promulgação da lei estadual no 11.257, de 28 de setembro de 1995, que oficializou a elevação Tamandaré para a categoria de município, portanto, ficou independente político-administrativamente de Rio Formoso, seu município-mãe.

O dia 28 de setembro já era histórico desde 1871, quando a princesa Isabel assinou a lei do ventre livre, que garantiu a liberdade aos filhos de escravos que nasceram a partir desta data. Assim, esta emancipação racial brasileira serviu para minimizar a vergonhosa escravidão que manchava por mais de três séculos, a história deste país. Pelo exposto, o dia 28 de setembro merece ser duplamente comemorado, já que representa dois fatos de libertações históricas que beneficiaram a população de Tamandaré.

Este município teve outros vínculos libertários, já que no Forte de Tamandaré ocorreu uma batalha onde morreram dezenas de pessoas favoráveis a Confederação do Equador (movimento de caráter separatista e republicano, contrário à centralização do poder imperial), somando-se ao fato atual dos cidadãos estarem interagindo na busca de tentar eliminar o racismo que ainda insiste em ocupar espaço entre alguns moradores e visitantes, embora de forma camuflada, porém, presente nas relações cotidianas. Assim, novamente algumas pessoas se unem em busca de uma nova emancipação, desta vez pela libertação social e cultural da população negra residente em Tamandaré, que tem sido subsidiado pelo Projeto Consciência Negra e por pessoas compromissadas em transformar o município num lugar mais igualitário. 


\section{RAÇA E RACISMO}

A grande maioria das publicações só se refere à problemática do negro sobre sua ocupação na sociedade, dando a entender que os brancos não precisam refletir sobre o seu espaço na sociedade e, como isso contribui para o preconceito racial. Excluir os brancos desta discussão é deixar de considerar um sistema de privilégios simbolizado pela cor da pele (BENTO, 2014; p. 27). De acordo com Santos (2012; p. 150) ao não dar visibilidade às desigualdades raciais existentes na sociedade brasileira, as organizações públicas são coniventes para a institucionalização do racismo.

A ideia de raça foi gerada entre os séculos XIX e XX em algumas definições que levaram em consideração as características da diversidade humana. Essa divisão contribuiu para aumentar o racismo e a relação de poder e dominação. Guimarães (2003; p. 95) explica que a divisão de raças não existe biologicamente, mas é encontrada apenas na sociedade como forma de classificar os seres humanos. Portanto, o que há são raças sociais e não biológicas. Assim, a aceitação da raça sustenta o racismo.

Depois que o Projeto Genoma Humano analisou a genética de diferentes raças humanas de todos os continentes, foi descoberto que não existe diferença genética entre os Homo sapiens. Assim, biologicamente a palavra raça passou a ser obsoleta. Entre os biólogos, o termo raça é utilizado apenas para diferenciar animais domésticos. Pelo exposto, raça é um conceito social e não biológico.

Saber como os negros eram vistos na sociedade escravocrata é importante para compreender o caminho percorrido até os dias atuais, com o surgimento do racismo moderno. Neste caso, significa que as pessoas identificam a existência do racismo, mas não se reconhecem no papel de preconceituosa, inclusive algumas apontam os negros como único responsável pelo próprio racismo (POTEAL e SPANIERMAN, 2012; p. 759).

A negritude, no território brasileiro, é o principal alvo de várias formas de descriminação racial. Com a existência de poucas reações contrárias, essas relações ficaram profundamente naturalizadas nas práticas sociais. Em função do ocultamento do racismo, que nos discursos e nas práticas sociais negam sua existência, é extremamente necessário analisar os discursos, as ideologias e as identidades étnico-raciais construídas, difundidas e naturalizadas em nosso meio social (SILVA, 2009). O fato acima mencionado é uma prática constante, embora se busque a sua invisibilidade.

Munanga (2003) sugere que na área da ciência biológica, a raça não é uma realidade biológica, mas sim um conceito cientificamente inoperante para explicar a diversidade humana. Porém, é a partir dessas raças fictícias ou "raças sociais" que se reproduzem e se mantêm os racismos populares. A classificação da humanidade em raças hierarquizadas deve-se à raciologia, que ganhou muito espaço a partir do início do século XX.

Maximino (2012) menciona o conteúdo das teses de dois cientistas, Eagleman e Mlodinov, os quais concluíram: "somos racistas por natureza", já que o cérebro, inconscientemente, é capaz de 
agrupar objetos e pessoas em categorias [...]. Ambos confirmaram antigas teses, inclusive de Freud, que garantem sermos vítimas de nosso inconsciente e do ambiente social. Neste sentido, Maximino pergunta: será que nossas escolhas já foram de antemão predeterminadas em nossos genes, pela bioquímica do cérebro ou pelas condições socioambientais? Na verdade, até que ponto somos escravos? Sugere que os cientistas supracitados partem da premissa questionável de que o racismo seja um conceito da biologia, quando, na verdade, trata-se de um conceito muito mais antropológico do que físico-biológico. E ele continua, senão, vejamos: ninguém nasce "racista". Então, o que acontece? Nós "aprendemos" a ser racistas! Se vamos "aprender" a lição ou rechaçá-la, sempre será uma escolha pessoal. Salvo as exceções, o ser humano, embora de certo modo condicionado ou influenciado por múltiplos fatores ambientais e congênitos, sempre pode decidir e será quase sempre livre para escolher. Comportamentos racistas decorrem da educação social (exemplos) que recebemos, portanto, não somos racistas por natureza, assim, é um erro grosseiro usar a biologia para justificar o racismo.

\section{EMPODERAMENTO COMO INSTRUMENTO DE LUTA SOCIAL}

No sentido do racismo ser desconstruído em Tamandaré, a contribuição do Projeto Consciência Negra é a de construir uma sociedade que abrace as desigualdades, além de incentivar os negros a se aceitarem plenamente, permitindo que a sociedade assim deva reconhecê-lo e valorizá-lo. Mas a luta contra o preconceito racial deve ser uma contínua missão em busca da libertação e da transformação social.

A partir dos primeiros momentos do Projeto Consciência Negra, ainda em 2014, o grupo envolvido nesse movimento passou a enfatizar mais diretamente as questões relacionadas ao preconceito e a discriminação racial. Posteriormente, existiu um constante trabalho no sentido de valorizar a luta do negro por uma sociedade mais justa. Daí, houve um despertar do grupo que passou a incentivar as pessoas, principalmente nas escolas, onde praticamente não se discutia sobre o assunto do negro, para que o tema fosse posto no cotidiano escolar e, com naturalidade que fosse conversado. Nesses diálogos escolares, buscou-se respostas de pessoas negras presentes, sobre os seus sentimentos e conflitos ao enfrentar uma sociedade preconceituosa. Nos debates, algumas perguntas eram realizadas e direcionadas aos participantes, tais como: por que não nos permitem ser negros? Por que não podemos assumir nossos traços, cabelos e cultura? Estas ficavam sem respostas dos participantes ou a reação era para explicar que não compartilhavam com esse tipo de atitude racista. No entanto, a verdadeira intenção das perguntas era servir para despertar as pessoas, que esse tipo de atitude não merece nenhum espaço no município de Tamandaré.

É notório que muitas pessoas negras não se afirmam como tal, se negam diante da sociedade, e, de maneira bem perversa, não se reconhecem como negro na frente do espelho, portanto, não conseguem se afirmar. Infelizmente todas essas negações, têm um porquê ou vários porquês. 
A sociedade brasileira precisa e muito refletir e aceitar com naturalidade a negritude das pessoas, embora a cultura do preconceito e discriminação racial esteja secularmente entranhada na vida dos indivíduos. Embora diante das injustiças sociais históricas, o povo negro deve se manter unido em busca desse grande ideal libertário. Não foi fácil os antepassados sobreviverem, mas para isto foi preciso muita luta, mesmo enfrentando as limitações da escravidão.

A princesa Isabel ao assinar a Lei Áurea, a história oficial passou a afirmar que foi um gesto de bondade, entretanto, foram quase três séculos de exploração da mão-de-obra da pessoa negra. Apesar de ninguém nascer escravo, porém, a organização social dos colonizadores brasileiros, impôs esse modelo de repressão. É comum as pessoas negras apresentarem comportamentos letárgicos, expondo sentimentos de inferioridade. Para chegar nesta situação diversos fatores colaboram, como: condições financeiras, oportunidade de emprego, escolaridade e a marginalização.

O projeto Consciência Negra trabalha o autoreconhecimento do ser negro, estimulando a valorização de suas forças e qualidades, na tentativa de firmá-lo enquanto negro. Com esse sentimento e comportamento, o negro não fica à deriva da sociedade preconceituosa que impõe a ideia destorcida, sobre o que vem do negro não presta.

O empoderamento das pessoas negras traz consigo toda a força de mais de quatro séculos de lutas, contra preconceito e descriminação racial, que persiste até os dias atuais. É importante ressaltar que a execução do referido Projeto vem provocando nas pessoas negras um grande despertar para o sentimento de pertencimento da sua origem, um empoderamento no que concerne à valorização e o reconhecimento do próprio eu.

É visível essa valorização a partir do comportamento e dedicação dos voluntários, alunos, professores e funcionários das escolas que se envolveram com os eventos. Muitos participantes, depois que vivenciaram esses encontros ocorridos em Tamandaré, passaram a soltar e a preservar os cabelos de forma natural, pois assumiram os cachos e, junto com eles a sua identidade de mulher negra. Essa evolução na forma de agir tem sido perceptível em momentos de conversas e observando as redes sociais, onde os(as) mesmos(as), se afirmam como negro(a), portanto, admitindo uma postura de afirmação da negritude diante da sociedade e, comumente exigindo respeito por parte das pessoas preconceituosas.

Segundo o dicionário do Aurélio (2018), a palavra empoderar significa dar ou adquirir poder ou mais poder e, empoderamento significa: ato ou efeito de empoderar ou empoderar-se. Continuando a busca nos dicionários, no Houaiss (2011, p. 557), a definição da palavra empoderamento é o ato, processo ou efeito de dar poder a alguém ou a um grupo, ou de alguém ou um grupo tomá-lo.

Para Valoura (2005) o educador Paulo Freire apresenta um conceito para pessoa, grupo ou instituição empoderada, é aquela que realiza, por si mesma, as mudanças e ações que a levam a evoluir e se fortalecer. Acompanhando as definições supracitadas, é possível a palavra empoderada ser relacionada aos movimentos sociais que envolvem as lutas do negro, especialmente por mais respeito 
e igualdade social. Diante do exposto, pode-se compreender o empoderamento como sendo mudanças que acontecem de dentro para fora, sobretudo, quanto a afirmação, o fortalecimento e a emancipação do eu. 0 negro se reconhecendo, se declarando e, lutando pela sua dignidade humana.

Em Tamandaré, o empoderamento das pessoas negras criou uma nova perspectiva de horizonte, fazendo com que as pessoas não aceitem com naturalidade as formas de preconceito e discriminação racial. Estas se apresentam por meio de brincadeira ou de ditados populares, portanto, chegam sutilmente, porém, expressando o mais puro e perverso preconceito racial. Esse modo de procedimento preserva a ideia de perpetuar formas lúdicas de agredir as pessoas negras. Os empoderados e envolvidos com o Projeto Consciência Negra não permitem mais este tipo de comportamento, assim sendo, em todas as ocasiões eles questionam e deixam bem claro que essa maneira de se expressar não é aceitável. É possível afirmar que só alcançaram esse nível de empoderamento porque se reconheceram como negros e, a partir desse reencontro, não se calam diante das pessoas preconceituosas, as quais paulatinamente estão visivelmente compreendendo que o racismo está perdendo o seu espaço em Tamandaré.

\section{O DESPERTAR DA EMANCIPAÇÃO RACIAL EM TAMANDARÉ}

Apesar de a pluralidade racial existir no território brasileiro desde a sua colonização, infelizmente pessoas racistas ainda se encontra com frequência, inclusive crianças e jovens que normalmente participam das manifestações discriminatórias, gerando sérios conflitos escolares. Os estudantes cientes de que os professores e funcionários não admitem tal procedimento nas escolas, geralmente realizam distante desses profissionais. 0 problema se alastra ainda mais porque a maioria dos atingidos não reage ou comenta sobre a agressão sofrida, assim, a escola e a família têm pouca percepção desta desprezível prática, portanto, não atuam de forma eficaz para reduzir e interromper o racismo. Assim, este tipo de prática discriminatória é negativo quando não é observada e combatida ainda no período escolar, tende a acompanhar o ser humano pelo resto da sua vida.

Em Tamandaré não é diferente do restante do país. Embora existam pessoas que não aceitem esse tipo de atitude, porém, pouco se empenharam em abraçar uma campanha contra o racismo. No entanto, desde a década de 1990 que o aluno do ensino fundamental, Romero Silva de Albuquerque, percebeu que a afirmação da negritude não era estimulada nas escolas, como deveria acontecer. Compreendeu que a ausência dessas discussões e a postura da sociedade que aprendeu a negar o ser negro, faziam com que as pessoas negras não se aceitassem, portanto, lhe era perceptível que alguns colegas negros não aceitavam as suas características naturais. Era um tempo que não se discutia assuntos da afirmação ou valorização da negritude. Essa falta de referência alimentou o sonho de criar em Tamandaré, um espaço para se debater sobre a consciência negra, numa perspectiva de 
valorização da cultura negra, da ancestralidade, da afirmação de suas tradições e do autoconhecimento.

A partir de 2006, os alunos graduados (Alberto José da Silva - Alemão; Cristiano José da Silva Bioco; Cícero Correia Silva de Barros - Pequeno Mestre e, Romero Silva de Albuquerque) da Associação de Capoeira Bem-te-vi, existente em Tamandaré desde 1996, ao ministrarem aulas de capoeira em algumas escolas desta cidade, diante da experiência vivenciada, sentiram a necessidade de iniciar um Movimento da Consciência Negra. Organizaram-se de maneira muito tímida, mas mesmo assim promoveram o primeiro encontro em 2007, com palestra sobre o negro na sociedade e roda de capoeira, apresentadas na Escola Santa Terezinha do Menino Jesus, no Centro de Solidariedade Padre Enzo (CSPE) e Educandário Nivaldo da Silva. Até o ano de 2013, outros pequenos eventos foram realizados extraoficialmente, principalmente nos dias 13 de maio e 20 de novembro; sempre em local público (na Praça da Liberdade, na Praça Estrela do Mar, no Forte de Tamandaré e na orla próximo à Igreja de São José) e nas escolas, (Santa Terezinha do Menino Jesus, no CSPE e no Educandário Nivaldo da Silva.).

Em 2014, o professor de educação física e de capoeira Romero Silva de Albuquerque, compreendeu que para atingir um público maior e a comunidade se sensibilizar com as injustiças sociais direcionadas ao povo negro, era necessário oficializar este evento. Assim, redigiu o Projeto Consciência Negra na cidade de Tamandaré-PE, e apresentou ao Centro de Solidariedade Padre Enzo (CSPE), onde ensinava capoeira. Neste mesmo ano, o Projeto teve culminância no dia 13 de maio, abrindo os trabalhos para o momento do dia 20 de novembro; foi considerado pioneiro nesta localidade e ocorreu na referida entidade educacional que o assumiu de imediato.

As coordenadoras pedagógica e do setor social do CSPE entenderam que para o Projeto Consciência Negra ganhar força e desbravar outros espaços, era necessário ser executado na rua, através de uma ação chamada Centro na Rua. Para tal conquista, os profissionais do CSPE trabalharam incansavelmente para as pessoas saírem do evento empoderadas e conscientes da sua história de luta.

Anualmente, o Projeto tem sido elaborado coletivamente por funcionários e voluntários do CSPE e, posteriormente apresentado às entidades parceiras. Nas metas constam reuniões em escolas e outras entidades, confecção de material de divulgação, a organização da infraestrutura dos eventos, entre outras demandas. Em todas as etapas do Projeto conta com a presença de voluntários.

O CSPE é direcionado ao atendimento de aproximadamente 500 crianças e adolescentes em situação de risco social. Para as crianças de 02 a 06 anos, oferece os serviços de Creche, escolar, recreação, esporte, lazer, etc.; entre 07 e 15 anos, participam de atividades e cursos no sistema de contraturno escolar, onde são oferecidos cursos de gastronomia, padaria, informática, capoeira, horta educativa, percussão, etc. Também centenas de famílias são beneficiadas com cursos diversificados e de curta duração. 0 suporte financeiro é oriundo de diversas fontes e de um forte voluntariado. Este empreendimento foi fundado em 1995, através do padre italiano Enzo Rizzo, quando idealizou o 
Projeto Tamandaré, executado na Creche Solidariedade, por ele construída, com o apoio de familiares e amigos italianos. Depois do seu falecimento em 2001, a Creche passou a se chamar Centro de Solidariedade Padre Enzo.

O Projeto sempre se chamou "Consciência Negra", porém, à cada ano muda o tema, com o objetivo de acompanhar as discussões atuais que envolve o assunto de racismo, preconceito e o genocídio da juventude negra. As edições anuais tiveram os seguintes temas: Às vezes me chamam de negro (em 2014 e 2015), Minha raça, minha cor, minha identidade (em 2016); Sou mulher, sou negra, sou guerreira (em 2017) e, Resistir para viver (em 2018).

O sucesso crescente tem relação direta com a dedicação e o comprometimento dos funcionários da instituição, contribuindo para os eventos trazerem na sua gênese a responsabilidade social que o Centro de Solidariedade Padre Enzo desempenha na comunidade, agregando valores tais como respeitos, dignidade, educação, compartilhamento, diálogo, participação e autoconhecimento.

0 evento é bastante divulgado e a comunidade é convidada para discutir algum tema ligado as condições do negro na sociedade. As crianças, os adolescentes e os familiares que fazem parte do CSPE através do Projeto Consciência Negra têm diversas possibilidades de pensar e repensar na negritude dos indivíduos e, no cidadão negro como um sujeito de direito.

Desde a edição de 2015, houve um compartilhamento crescente com as escolas da rede pública e privadas de Tamandaré, também se buscou parcerias com os comércios e as instituições locais. Entretanto, na fase de pré-evento de 2018, foram organizadas várias palestras para que os alunos e professores fossem previamente estimulados a refletirem sobre os temas abordados, tais como a depreciação da imagem da mulher negra, as características do negro estarem fora dos padrões de beleza, etc. Na divulgação do evento, a população foi convidada através de reuniões, carros de som, convites (Figura 1) e em redes sociais.

Figura 1. Convites dos eventos da Consciência Negra. Tamandaré - 2017 e 2018.
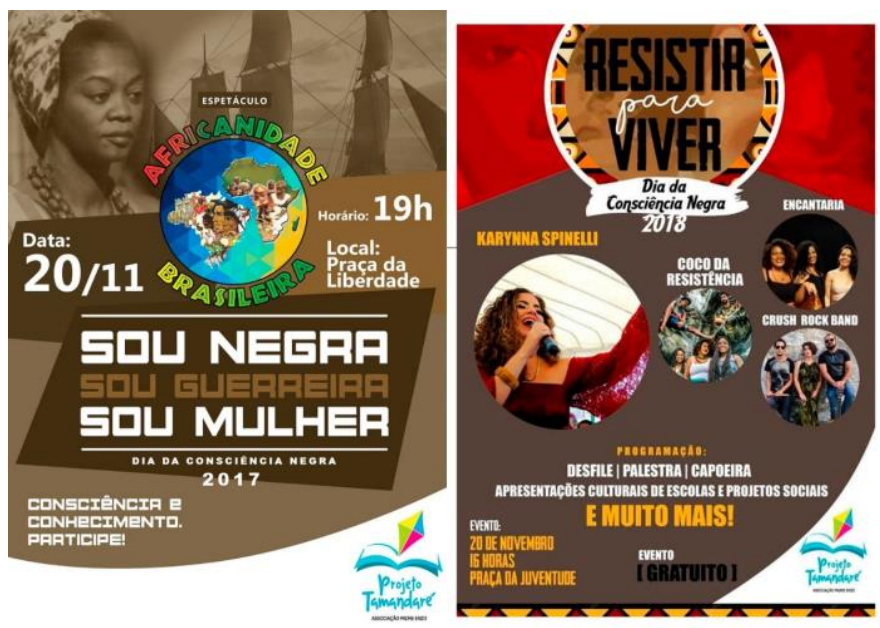

Fonte: arquivos do projeto. 
A edição de 2018 foi um fato extremamente especial. Deixou sua marca em centenas de tamandareenses e visitantes, que ficaram encantados com energia que as pessoas levaram para a Praça da Juventude. A culminância do Projeto Consciência Negra ocorreu em 20 de novembro na Praça da Juventude, no centro de Tamandaré, das $18 \mathrm{~h}$ às $23 \mathrm{~h}$ (Figura 2).

Figura 2. Evento da Consciência Negra. Tamandaré, 20/11/2018.
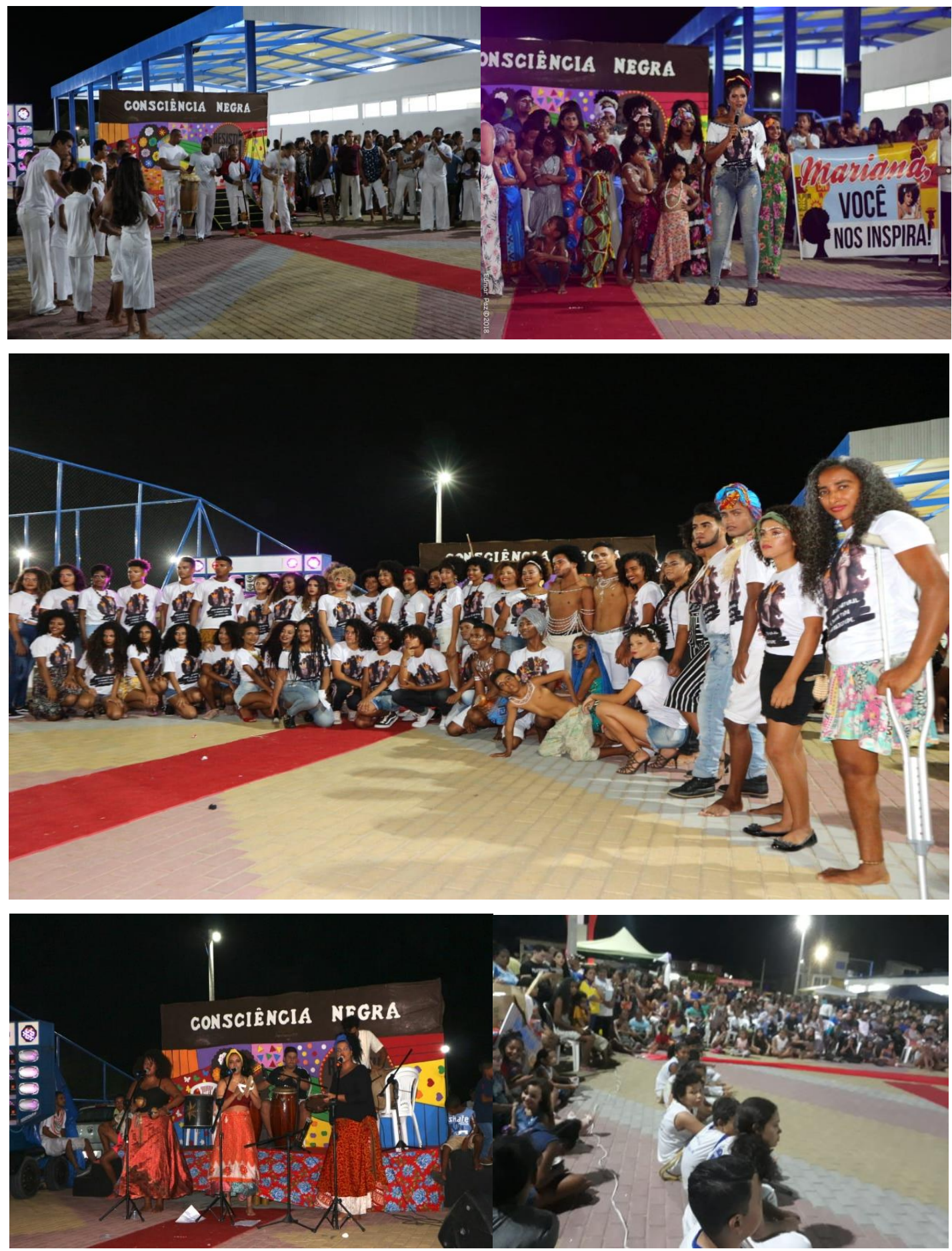

Fotos: Karlota - CSPE; Edmar Paz. 
O pedido por respeito foi lançado, a mensagem foi repassada, as crianças protagonizaram belos espetáculos, contaram a sua história através da cultura dos seus ancestrais. Adolescentes, jovens, adultos e idosos afirmaram a sua negritude, se apresentaram para a comunidade enquanto negro, e, exigiram respeito para com o sujeito de direito ali representado, as suas manifestações culturais, a sua culinária, o seu vocabulário, os seus artesanatos, os seus estilos de se vestir, as suas características físicas e a sua fisionomia.

Foi um momento de riquíssimas trocas de experiências, quando o público-alvo teve a oportunidade de expor sobre a sua negritude, no caso do negro, e sobre o respeito, no caso das pessoas que não são negras. Na praça ficaram centenas de pessoas que assistiram as atrações que eram apresentadas pelas crianças, adolescentes, adultos e idosos; pessoas que tiveram uma conscientização prévia, através de várias reuniões, para compreender na essência os resultados que seriam difundidos durante o evento. Contou com uma vasta programação, com destaque para apresentação de poesias, cordéis, cartazes, músicas, depoimentos, capoeira, testemunhos, sugestões para futuras estratégias para o sucesso prático do Projeto Consciência Negra. A idade das pessoas que participaram das apresentações, variou entre 5 e 70 anos, os quais defenderam a cidadania de todos os tamandareenses, sem distinção de cor.

Na ocasião, Mariana Andrade (Figura 2, em destaque na segunda foto) foi homenageada por ser considerada um exemplo na luta do negro deste município, ao incentivar as pessoas a se amarem do jeito que Deus as fez.

As atrações apresentadas no evento de 2018 contribuíram em aproximar a população local da cultura negra, deixando bem claro sobre a sua força cultural. Na ocasião foram enfatizadas as belezas naturais dos negros, a importância da preservação dos cachos e a alegria da dança. Cantaram sambas, teve roda de capoeira, o coco-de-roda, diversos testemunhos, recitaram poesias e tocaram instrumentos tradicionais cantando lindas canções. Foi extremamente positivo para todos os presentes, inclusive para as crianças negras, as quais participaram ativamente do evento. Enfim, foi praticamente unânime entre as centenas de pessoas, ao afirmarem que se orgulhava da sua cor e demais características genéticas.

A perspectiva para o futuro é no sentido de anualmente aumentar o contingente de pessoas que assistem o evento e, principalmente daqueles que participam diretamente, pois esses últimos tendem a trabalhar mais ativamente para alcançar os objetivos do projeto. De modo geral, entre os municípios do litoral sul de Pernambuco, Tamandaré se destaca em consolidar esse movimento de equidade racial com grande aceitação popular, fruto do Projeto Consciência Negra. 


\section{ALGUNS DEPOIMENTOS}

Para divulgar o sentimento de pessoas que buscam no Projeto Consciência Negra a superação de preconceitos, a valorização de sua autoestima e a conscientização da população de Tamandaré, a seguir consta a síntese do pensamento e experiência de alguns jovens desta localidade, extraídos através de questionários:

- Entrevistado 1 (16 anos): "na escola e pelo instagram já sofri preconceito. Primeiro fiquei muito mal, fiquei me questionando o porquê de ser negro e ter cabelo crespo, porém, o Projeto ajudou bastante na minha autoestima, principalmente, diante da sua mensagem de que somos todos iguais, portanto, o problema está nas pessoas que não aceitam as diferenças. Hoje não tenho motivo para ficar triste, aceito naturalmente as minhas características. O Projeto lembra a luta do negro, da sua força e sua história".

- Entrevistada 2 (15 anos): "já sofri preconceito na escola, em espaço público e na família. No início eu não entendia bem e me influenciava negativamente, principalmente quando a família dizia que o meu cabelo era feio. Para evitar tal situação, comecei a alisar o cabelo, pra tentar me encaixar num modelo construído socialmente de menina bonita. Na realidade, foi depois deste Projeto que eu adquiri a liberdade para assumir minhas raízes. Ele tem muita importância para os jovens daqui; eu mesma não teria conseguido me desprender dos padrões que me foram impostos, sem a ajuda deste Projeto que deve continuar sempre, pois conscientiza as pessoas, desmistifica todas as inverdades sobre as raízes brasileiras e, dá apoio para que os jovens se reencontrem".

- Entrevistada 3 (37 anos): “o preconceito que sofri foi familiar, principalmente, quando resolvi assumir meu cabelo afro, mesmo assim, jamais penso em colocar química nas minhas madeixas. Este Projeto tem um papel importantíssimo para a nossa sociedade, que através dele vem despertando e se valorizando".

- Entrevistada 4 (17 anos): "sofri situação preconceituosa na escola, espaço público e na família, desde os 9 anos. Na época eu ficava perguntando o que tinha de errado em mim, para as pessoas fazerem comentários comigo, principalmente me chamando de cabelo de "Bombril". Fui crescendo e me afirmando todos os dias e, ajudo outras pessoas a se afirmarem também, seja no cabelo, na sua cor, etnia. O Projeto Consciência Negra contribuiu com este processo de aceitação, nos alertou que temos o nosso espaço, mas que temos que lutar por nossos direitos. Ele despertou nas pessoas, o entendimento da importância que o negro tem na história do país, e devemos aceitar com naturalidade, o nosso o nariz, boca, dentes, cabelos e a nossa cor. Esse Projeto nunca deveria acabar, muitos jovens precisam ter noção e conscientização do que é o negro. Ainda há muitas pessoas que precisam se afirmar e aos poucos vou à luta, o que eu mais quero é que tenhamos espaço pra falar e se expressar".

- Entrevistada 5 (17 anos): "enfrentei preconceito na escola e na família, desde os 11 anos; na época chorava muito, era só o que eu conseguia fazer. Hoje, supero não aceitando esse tipo de tratamento negativo. $O$ Projeto ajudou a ver que sou mais capaz do que pensava, me ajudou a sentir como eu era de 
verdade, me fez florescer novamente. Para Tamandaré, o Projeto deixa-nos ver que cada um tem algo antes nunca falado para ninguém, mas que com essa ajuda as pessoas irão livrar desse mal. Com a continuidade do Projeto iremos a procura de pessoas que estão precisando de ajuda para florescer, $e$ mostra que juntos iremos vencer o preconceito e o racismo".

- Entrevistada 6 (17 anos): "já sofri preconceito na escola, nos espaços públicos, no trabalho e na família, desde meus 12 anos. Em todas as ocasiões, ficava triste sofrendo calada. Hoje, até consigo sorrir. Este Projeto influenciou para que elas assumirem quem são, e não o que a sociedade deseja".

- Entrevistado 7 (38 anos): "já sofri preconceito em espaço público. Minha reação é sempre de indignação, pois moramos num país em que mais de 60\% da sua população é negra e indígenas, mesmo assim nos deparamos com esses atos preconceituosos o tempo todo e, em todos os lugares. A melhor forma de superar tudo isto, é acreditar que um dia uma nova geração seja extremamente educada e consciente, para que a nação brasileira não possa ser dividida por cor, religião, grau social, etc. O Projeto deve expor a aceitação da beleza negra, mas sobretudo a intolerância do sistema que tanto nos oprime. Pela sua importância em nossa cidade, peço aos organizadores que continuem com esse belíssimo trabalho, pois acredito numa futura geração sem preconceito racial.

- Entrevistada 8 (15 anos): "já sofri preconceito na escola, em espaço público e na família, tendo despertado para essas ações à mim dirigidas a partir dos meus 12 anos. Os preconceitos sempre foram vieram em forma de palavras maldosas, com a intenção de me sentir inferior, por conta das minhas características físicas. Infelizmente o racismo estrutural ainda existe em nossa sociedade. Existem coisas que pude superar, porém, outras não. $O$ preconceito deixa cicatrizes que vez por outra é aberta. O Projeto Consciência Negra tem contribuído em superar tais constrangimentos, além de ajudar de forma surpreendente, no meu processo de afirmação como negra, por exaltar a beleza negra e a história de luta que existe em cada um de nós. O Projeto traz outra visão sobre o negro para a comunidade, e expõe sobre a diversidade de belezas e culturas trazidas pelos africanos escravizados. Pelo exposto, é de extrema importância que haja uma continuidade do Projeto, para que mais pessoas tenham contato com essa realidade e saibam respeitar o físico e a cultura de cada um, de forma singular".

Em conversas informais com as pessoas negras, é quase unanimidade afirmarem que já foram humilhadas por vários motivos, especialmente na escola, em locais públicos, por familiares e vizinhos, a principal motivação é direcionada aos cabelos, que são chamados de cabelo de bucha, de cabeça de cupim, leão, cabeça de parabólica, de capacete, etc. Mas também é bastante comum afirmarem que o Projeto Consciência Negra tem trazido momentos de bons entendimentos psicológicos, fazendo com que reajam com naturalidade, porém, com firmeza para afirmar que somos todos iguais. Muitos descobrem a sua força libertária, entendendo que independente de qualquer opinião alheia, decidem por se aceitarem, assim, muitas coisas mudam em suas vidas, que se torna mais positiva. Muitos jovens repetem que não aceitam mais ficarem aprisionados a velhos conceitos opressivos, que diminuem seu amor próprio. Em Tamandaré, para a grande parte da população negra, o importante é viver sem se 
importar com o que os outros vão falar, pois tem que manter viva a essência da busca da felicidade que tem dentro de cada um.

Essa nova geração de tamandareenses, depois da existência do Projeto Consciência Negra, criou uma grande força de vontade em escrever um novo capítulo na história deste município. São pessoas comprometidas em assumir suas características morfológicas e culturais, além de possuírem um elevado grau de dinamismo, suficiente o bastante para convencerem a população de que somos todos iguais e, de reagirem diante de arcaicos preconceitos. Diferente da forma de agir da geração negra de outrora, que mesmo com a abolição da escravatura, se acomodou e aceitava cabisbaixa, todos tipos de humilhação e perseguição.

Pelo exposto, o referido Projeto tem seus objetivos plenamente alcançados, portanto, a sua culminância no dia 20 de novembro de cada ano, deve ser oficializado no calendário municipal, por ter se transformado num importante patrimônio cultural.

\section{CONSIDERAÇÕES FINAIS}

O Projeto Consciência Negra surgiu da necessidade de despertar nas pessoas que residem ou visitam Tamandaré, que em pleno século XXI, o preconceito racial já deveria fazer parte do passado. Também, serve como alerta para que os negros se aceitem plenamente, com todas as características culturais e estéticas.

A resistência individual e coletiva é a marca da condição negra, estando esses últimos bem representados pelos quilombos pernambucanos. No supramencionado município, a aceitação crescente deste Projeto é a maior demonstração popular de resistência em prol do movimento negro.

Os entrevistados mencionaram terem sofrido preconceitos no Instagram, no trabalho, na escola, em espaços públicos, mas principalmente da própria família. A ofensa racial existente entre familiares, à primeira vista é inadmissível, por adentrar nos lares e intervir diretamente no convívio afetivo entre os seus componentes. Essa violência é mais comum entre membros de famílias interraciais, quando o fenótipo os diferencia dos demais, portanto, aqueles com estética mais aproximada aos padrões da branquitude se acham no direito de discriminar seus familiares possuidores de características marcadamente da negritude, assim sendo, promovem hierarquias raciais que geram relações interfamiliares extremamente negativas.

A desconstrução do racismo tem sido trabalhada com a participação popular, desde 2014, através da execução do Projeto supracitado. Já é visível a evolução entre as pessoas, independentes de cor, que passaram a divulgar e agir de acordo com os objetivos propostos.

Como é perceptível, a força jovem dos negros de Tamandaré tem lutado por sua própria aceitação e, conseguido mudar a mentalidade de várias pessoas preconceituosas que se sentiam 
pertencentes à outra raça, porém, trata-se de uma pseudorraça, já que biologicamente essa classificação não existe.

0 apoio das comunidades escolares tem demonstrado ser imensamente importante, como forma de propagar mais rápido e de forma mais abrangente, portanto, são importantes facilitadoras na ampliação do envolvimento dos moradores locais e visitantes.

Diante do crescimento do evento ocorrido em 20 de novembro de 2018, quando, mais que triplicou o número de participantes em relação ao ano anterior, é possível estimar que o engajamento espontâneo da população proporcione resultados cada vez mais positivos e, num futuro próximo, Tamandaré tende a festejar a conquista da conscientização da população local e também, de seus visitantes.

\section{REFERÊNCIAS}

AURÉLIO. Dicionário do Aurélio Online. 2018. Disponível em: <https://dicionariodoaurelio.com/ empoderar>. Acesso em: 08 de abril de 2019.

BENTO, M. A. S. Branqueamento e branquitude no Brasil. In: CARONE, I. \& BENTO, M. A. S. (Orgs.). Psicologia social do racismo: estudos sobre branquitude e branqueamento no Brasil. Petrópolis: Vozes, 2002, p. 25-57.

HOUAISS. Dicionário Conciso. Instituto Antônio Houaiss. São Paulo: Moderna, 2011.

IBGE - Instituto Brasileiro de Geografia e Estatística, 2018. Município de Tamandaré. Disponível em: https://cidades.ibge.gov.br

/brasil/pe/tamandare/panorama. Acesso em: 30 de março de 2019.

MARCUSSI, A. A. Diagonais do afeto: teorias do intercâmbio cultural dos estudos da diáspora africana. São Paulo: Intermeios (FAPESP), 2016, 258p.

MAXIMINO, S. M. O cérebro racista. Disponível em: https://www.geledes.org.br/o-cerebro-racista/. 2012. Acesso em: 23 de março de 2019.

NOGUEIRA, I. B. Significações do corpo negro. Tese de Doutorado (Psicologia Escolar e do Desenvolvimento Humano). Universidade de São Paulo. São Paulo. 143p. 1998.

PINHEIRO, B. Caminhos e descaminhos do pensamento cultural na histografia da diáspora africana. Tempo e Argumento, v. 9, n. 22, p. 487493, 2017.

POTEAL, P. V.; SPANIERMAN, L. B. Modern racism attitudes among white students: the role of dominance and authoritarianism and the mediating effects of racial-color blindness. The Journal of Social Psychology. v. 152, n. 6, p. 758774, 2012.

REIS, J. J. Resistência escrava na Bahia "podemos brincar, folgar e cantar...". O protesto escravo na América. Afro-Ásia, n. 14, p. 107-123, 1983.

SANTOS, Alessandro. 0. Superar o racismo e promover a saúde da população negra: desafios para o trabalho de prevenção ao HIV/Aids no Brasil. In: PAIVA, V.; AYRES, J. R. \& BUCHALLA, C. M. (Orgs.). Vulnerabilidade e Direitos Humanos. Prevenção e Promoção da Saúde. Da doença à Cidadania. Curitiba: Juruá Editora, 2012, p. 145163.

VALOURA, L. C. Paulo Freire, o educador brasileiro autor do termo empoderamento, em seu sentido transformador. São Paulo: Instituto Paulo Freire, 2006. Disponível em: <https://www. researchgate.net/publication/303912423_Paulo _Freire_o_educador_brasileiro_autor_do_termo_E mpoderamento_em_seu_sentido_transformador >. Acesso em: 03 de abril 2019 